\title{
Gabriel Vommaro, La larga marcha de Cambiemos. La construcción silenciosa de un proyecto de poder, Buenos Aires, Siglo Veintiuno Ediciones, 2017, 363 pp.
}

El último libro de Gabriel Vommaro permite comprender el período formativo y la llegada al poder de Cambiemos, la coalición política que gobierna la Argentina desde diciembre de 2015. Lo hace a la luz del análisis de las trayectorias y las mediaciones de un conjunto de actores socio-políticos que contribuyeron a la construcción de la maquinaria política de Propuesta Republicana (PRO), el partido de centroderecha que encabeza esa alianza. Explicar ese proceso es importante por dos razones. La primera, porque es la primera vez desde la ampliación democrática producida en el país a comienzos del siglo XX que una fuerza política de ese espectro ideológico, conducida por dirigentes procedentes de las clases altas o medias altas, arriba al gobierno nacional a través de elecciones abiertas y legítimas. La segunda, guarda relación con la opción metodológica del autor ya que, al indagar un fenómeno político de envergadura dándole un lugar privilegiado a la voz de los propios actores, ofrece una representación nativa del universo indagado.

La larga marcha de Cambiemos... es un libro de sociología política interpretativa, que principalmente se encuentra en diálogo con la "escuela” francesa nutrida por Michel Offerlé, Frédéric Sawicki, Jacques Lagroye, entre muchos otros. También con las investigaciones de la generación de sociólogos argentinos de la que forma parte el autor que, alentada por las políticas científicas nacionales progresivas desplegadas entre 2005 y 2015, desarrolló proyectos colectivos de gran envergadura a través de los cuales se alcanzaron resultados muy significativos en cuanto a los atributos, las características y las prácticas de las élites de poder. 
Este tercer libro del autor sobre PRO, es tributario de ese contexto. Combina conocimientos teóricos y evidencia empírica sólida con una escritura muy amena, destinada a un público que excede las fronteras de la comunidad académica. Una vez más, Vommaro despliega su capacidad tanto para construir, cotejar o reinventar herramientas analíticas o nociones de gran impacto entre los cientistas sociales. No busca una aproximación modelizante a la hora de analizar una coalición. Por el contrario, deja hablar a sus fuentes -orales, escritas y audiovisuales- para profundizar en el estudio de "esos espacios e instituciones formales e informales que no integran los estatutos de la institución, pero son fundamentales para entender el modo en que un partido vive de manera cotidiana, recluta militantes y cuadros políticos y formatea sus visiones del mundo” (p. 131). Con ese objetivo, indaga los mecanismos de construcción de la fuerza política que reconoce como leader a Mauricio Macri, en especial los llevados a cabo por dos colectivos socio-profesionales que impulsaron la formación y consolidación de PRO: abogados de empresas y managers. Su hipótesis central, que tiene mucho potencial explicativo en tanto habilita la indagación de otras fuerzas partidarias, es que la conexión de "PRO con ciertos mundos sociales de pertenencia permite una imbricación del partido en espacios sociales en los que se nutre de militancia, visiones del mundo y un ethos político que moviliza maneras de actuar exteriores a la política” (p. 28). Esas conexiones son potenciadas en dos momentos específicos: el de gestación, que ronda la crisis generalizada de 2001 y el de mayor incorporación de cuadros manageriales, en torno a la crisis planteada por las corporaciones rurales en 2008, que contribuyó para que las clases medias y medias altas reconocieran el imperativo moral de “dar el salto” y "meterse en política” para "salvar al país de la chavización” en la que desembocarían las políticas del kirchnerismo.

Luego de la introducción, el texto se organiza en cinco capítulos, a lo largo de los cuales se reconstruyen la labor de reclutamiento y organización realizada por las fundaciones y, dentro 
de ellas, los individuos que constituyen el entorno partidario. En el primero, se describe al grupo de jóvenes abogados de empresas que proponen una alternativa al clientelismo a la hora de atender a las necesidades de los afectados por la crisis de 2001, estimulan a emprendedores sociales barriales y proponen una nueva relación con el Estado. Estas acciones son realizadas a través de fundaciones que conectan el mundo social con dos partidos políticos minoritarios de centroderecha implantados en la Ciudad Autónoma de Buenos Aires y nutridos por el mismo segmento social, que se fundirían en PRO, movimientista y pragmático, bajo el liderazgo de Macri.

Las acciones de mediación y de traducción del mundo social al político, son exploradas en adelante en torno a los managers, actores centrales del capitalismo globalizado. Se los indaga como grupo y a la luz del modo en que tramitan su incorporación y permanencia en lo público. También de las formas organizativas que activan para que otros empresarios den "el salto". En ese sentido, se destaca la actividad de Generación 25 (G25), fundación destinada a la formación de futuros políticos que, a la hora de reclutar managers, apelará al temor a la “chavización” y a la oposición al kirchnerismo que atentaba contra el libre mercado y sus valores -nunca demasiado explicitados. El relato caracteriza el mundo empresarial, la sociabilidad de los managers y su búsqueda de prestigio social en lo público una vez que alcanzaron su techo en el ámbito privado.

Luego, se analizan diferentes vías por las cuales que esta minoría política intensa se prepara para la lucha política y se expande en el orden nacional. Un foco de atención es por la rama femenina de G25, que organiza un sinnúmero de encuentros formales e informales, tales como reuniones de pequeños grupos realizadas en la intimidad de los domicilios particulares con presencia de políticos de PRO, encuentros de mayor escala con intervención de personalidades con reconocimiento público (un rabino mediático, un cómico), instrucción en 
el manejo de redes sociales para multiplicar a los agentes de PRO. También se analiza la expansión desde Capital hacia otros distritos para alcanzar implantación nacional, mediante contactos con empresarios del interior que siguen criterios reputacionales, sin eludir la fotografía de grupos étnicos marginalizados.

Los managers reconocen los costos y beneficios de incorporarse al universo de lo público. Si los principales beneficios son morales y simbólicos, derivados del prestigio de "salvar a la república” una vez que los más capacitados lleven al ámbito público la lógica del trabajo organizacional y del funcionamiento de la empresa, los costos remiten al impacto que conlleva esa decisión en una baja en los ingresos individuales, con los ajustes familiares que implica. En vísperas de las elecciones que llevaron a Macri al gobierno, se describe el funcionamiento de su maquinaria política y el modo en que las diferentes categorías de participantes -managers, miembros del semillero que esperan nutrir cargos, adherentes, y hasta sus familias- se involucran en actividades tales como las que rodean el trabajo de fiscalización electoral, las que, realizadas de manera eficaz y gratuita, lo que les refuerza la convicción sobre su superioridad moral.

El último capítulo analiza las acciones de los managers luego de ganar las elecciones y llegar al gobierno. Son indagadas sus preferencias por cargos ejecutivos, sus prejuicios hacia el funcionamiento del Estado y, en contrapartida, su posterior valoración del empleado público y los aprendizajes que realizan. También se analiza el impacto de incorporar managers: se multiplican las dependencias estatales para tornar más eficiente la gestión, se aumentan salarios para atraer a otros managers, y se observa la reacción ante la caracterización del gobierno como CEOcracia.

El libro cierra con una recapitulación articulada por el objetivo general y la hipótesis, pero también introduce preguntas prospectivas, acerca de las posibilidades de transformación de un 
país de cultura plebeya y de que esta fuerza política establezca una dominación legítima y duradera.

Por todo lo dicho, La larga marcha de Cambiemos... se constituye en un libro de lectura ineludible para comprender qué hay por detrás y por debajo de la organización política que conduce la Argentina. Cabe decir también que, como lectora, me he sentido provocada e interpelada por el libro. Para dar cuenta de los años invertidos en la construcción del proyecto de poder del PRO, una fuerza de centroderecha modernizante, el autor escogió un título impactante, posible de asociar a la "Larga marcha" la de los comunistas chinos que derivó en la instauración de la República Popular China, un proceso que se encuentra en las antípodas del caso analizado. El título de un capítulo, “A las armas, ciudadanos”, evoca versos de la Marsellesa que aluden al deber del ciudadano-soldado en cuanto a defender a la patria aun derramando su sangre; esta concepción es difícil de vincular -al menos a priori- al comportamiento de los representantes del capitalismo flexible internacionalizado que son los managers. Un tercer elemento de provocación es el epígrafe del inicio, tomado de un testimonio: “... espero que la gente como vos tenga la capacidad y la apertura, porque muchas veces tienen prejuicios contra el PRO, para mirarlo académicamente, históricamente”. Es prácticamente un límite a la posibilidad de tomar distancia con el relato, a realizar una lectura crítica.

Es que el autor construye la obra dejando hablar a los involucrados en ese proyecto de poder. Desde una perspectiva cuasi etnográfica, Vommaro otorga estatuto a la palabra de los entrevistados, y ofrece una lectura novedosa, de primera mano, de la perspectiva de quienes se introducen en política, entrecruzan su mundo social de pertenencia con el político mediante instancias formales e informales, incorporan el lenguaje del mundo de los negocios a la política. En ese sentido, pone en valor la autorrepresentación de los propios actores. Ahora bien, esa 
elección metodológica supone un riesgo que es el de ofrecer una imagen voluntarista de abogados de empresa y managers, que argumentan dar "el salto” a la política para salvar al país. Es probable que si esa imagen incontaminada fuera cruzada con preguntas acerca de los intereses que representaban esos actores que se sumaron a la construcción de un partido que asume una política económica pro-mercado, la lectura cambiaría. En un sentido similar, pensar la relación con los medios de comunicación, en especial en cuanto al ida y vuelta entre la tematización de problemas -entre otros, el temor a la "chavización”-, su instrumentalidad para potenciar el discurso político de PRO y su impacto en la sociedad, la comprensión de la construcción de un proyecto de poder que anuncia el título sería más compleja y abarcativa.

Con todo, esta excelente obra deja la impresión de estar asistiendo a una nueva y, sin lugar a dudas, diferente versión de la política notabiliar en la Argentina, protagonizada por individuos que intentan revertir en lo político la posición de superioridad alcanzada en el universo social y económico. En la visión de sí mismos, interpelados por razones morales, asumen la responsabilidad republicana, alcanzan el gobierno e intentan reinsertar al país en el mercado internacional. Finalmente, al construir una fuerza política novel, obtienen ganancias de fundador, es decir, logran rápidas incorporaciones y promociones desde una maquinaria novel, que promete un siempre indefinido y polisémico cambio.

Marcela Ferrari Universidad Nacional de Mar del Plata - CONICET marcelapatriciaferrari@gmail.com 